\title{
Dinâmica do uso e cobertura da terra em Projeto de Desenvolvimento Sustentável na região da rodovia Transamazônica, Pará
}

\section{Land use and land cover dynamics in a sustainable development project in the transamazon highway region, Pará state, Brazil}

\author{
Orlando dos Santos Watrin 1 \\ Thamyres Marques da Silva² \\ Roberto Porro ${ }^{3}$ \\ Moisés Mourão de Oliveira Jr. ${ }^{4}$ \\ Amanda Pinoti Belluzzo ${ }^{5}$
}

\author{
Palavras-chave: \\ Dinâmica da paisagem. \\ Geotecnologias. \\ Análise espacial. \\ Projeto de assentamento.
}

\begin{abstract}
RESUMO
A região da rodovia Transamazônica, no estado do Pará, constitui uma das áreas críticas de desflorestamento na Amazônia, visto as transformações socioeconômicas que tem atravessado. Este trabalho analisa mudanças espaçotemporais do uso da terra e seus impactos na cobertura vegetal no Projeto de Desenvolvimento Sustentável Virola-Jatobá, Anapu, Pará, no período de 1984 a 2015. Como suporte principal destas análises, foram utilizadas imagens Landsat, processadas e analisadas a partir da plataforma Spring. Nos primeiros anos de análise, registrou-se taxas de desflorestamento muito modestas, só atingindo um incremento mais expressivos sete anos após a criação do PDS, mas, mesmo assim, em um patamar muito baixo. Como reflexo, a paisagem desta área é dominada por áreas florestais, sendo as classes de uso da terra associadas principalmente às pastagens, já que as áreas agrícolas são muito modestas. Em geral, as áreas florestais apresentaram altas taxas de estabilidade. Dentre as classes de uso da terra, as pastagens apresentaram taxas de estabilidade expressivas, apesar de a classe Pasto Sujo ter registrado certa dinamicidade.
\end{abstract}

\footnotetext{
${ }^{1}$ Embrapa Amazônia Oriental - EMBRAPA/ CPATU. Belém, PA, Brasil. orlando.watrin@embrapa.br

${ }^{2}$ Universidade Federal Rural da Amazônia, Belém, PA, Brasil. thamyresmsilva12@gmail.com

${ }^{3}$ Embrapa Amazônia Oriental - EMBRAPA/ CPATU. Belém, PA, Brasil. roberto.porro@embrapa.br

${ }^{4}$ Embrapa Amazônia Oriental - EMBRAPA/ CPATU. Belém, PA, Brasil. moises.mourao@embrapa.br

${ }^{5}$ Fundação de Ciência, Aplicações e Tecnologias Espaciais - FUNCATE. Belém, PA, Brasil.

amanda.belluzzo@gmail.com
} 


\section{Keywords:}

Landscape dynamics.

Geotechnology.

Spatial analysis.

Settlement project.

\begin{abstract}
The Transamazon highway region in the state of Pará is critical for Amazon deforestation due to socioeconomic transformations it has undergone. This work analyzes spatial and temporal changes in land use and its impacts on land cover in the Virola-Jatobá Sustainable Development Project (PDS) in Anapu-Pará, from 1984 to 2015. The study was mainly conducted through processing and analyzing Landsat scenes using the Spring platform. Very modest rates of deforestation were registered in the initial years analyzed. More substantial increments were reached seven years after the formation of the PDS, but nevertheless still at a low level. Consequently, forest is the predominant land cover in the PDS, followed by pasture, because agricultural areas are modest. In general, forested land presented high stability rates. Among other land use classes, pastures also presented significant stability, although the class weedy pasture showed some instability.
\end{abstract}

\section{Introdução}

Os processos de mudança do uso e da cobertura da terra constituem um importante tema da agenda das pesquisas globais de meio ambiente por modificarem o balanço energético e influenciarem o clima, pois promovem a alteração do albedo terrestre, da composição química da atmosfera e dos ciclos biogeoquímicos (FOLEY et al., 2005; VERBURG et al., 2009; LAURANCE et al., 2011). Considerado como um dos fatores mais impactantes nesses processos, o desflorestamento global foi avaliado por Hansen et al. (2013), no período entre 2000 e 2012, possibilitando estimar que $32 \%$ das perdas globais de cobertura vegetal são oriundas de florestas tropicais, sendo quase a metade destas perdas associadas à América do Sul.

No caso da Amazônia, a conversão de floresta primária para outros usos da terra vem ocorrendo a partir da década de 1970, em particular na região crítica conhecida como "Arco do Desflorestamento", dentro do processo de dinâmica de uso e cobertura da terra na região. Segundo Sorrensen (2009), tal processo comumente tem início com o corte seletivo de madeira de forma sucessiva até a eliminação de indivíduos adultos das espécies comerciais. Tem-se como prática comum o uso do fogo para preparo de área para implantação de sistemas agropecuários, principalmente pastagem, o uso da terra de maior relevância em termos de áreas antropizadas na Amazônia (PROJETO TERRACLASS, 2014; PROJETO MAPBIOMAS, 2019). Após a perda da produtividade, pelo manejo inadequado, muitas destas áreas são abandonadas, favorecendo o processo de sucessão vegetal natural.

Em resposta às necessidades crescentes de adequação ambiental que demandam reduções nas taxas de desflorestamento e no uso do fogo na Amazônia, no contexto das 
mudanças climáticas globais, vêm sendo implementadas na região políticas e programas públicos para a conservação ambiental, muitos capitaneados pelo Ministério do Meio Ambiente. Dentre essas iniciativas figuram aquelas baseadas em ações coletivas locais, como a instituída pelo INCRA, criando a modalidade de regularização fundiária conhecida como Projeto de Desenvolvimento Sustentável (PDS), conforme a Portaria INCRA 477/1999 (INCRA, 1999), modificada pela Portaria 1040/2002 (INCRA, 2002). Tal medida constitui uma resposta em face das restrições para a criação de projetos de assentamento de reforma agrária em áreas florestadas na Amazônia, como previsto pela Lei 11.284 de 2006 (BRASIL, 2006).

Conforme INCRA (1999) e Porro et al. (2015), o PDS constitui uma modalidade de assentamento em que não ocorre titulação, mas sim a emissão de Contratos de Concessão de Direito Real de Uso (CCDRU) que podem ser em nome de uma ou mais associações que congregam as famílias beneficiárias assentadas. Comparado a outras modalidades fundiárias, como Reservas Extrativistas, os beneficiários de PDS podem ter perfis e práticas de agricultores familiares com maior integração ao mercado, cuja atividade principal não seja a extrativa.

Em cada PDS existem Áreas de Reserva Legal (ARL) e Áreas de Uso Alternativo (AUA). A ARL em PDS pode ser utilizada somente de forma coletiva, a partir de planos de manejo florestal sustentável que deverão ser aprovados por órgãos ambientais. Já a AUA é explorada em regime familiar, em lotes distribuídos pelo INCRA a cada família beneficiária. Assim, o PDS constitui modalidade ambientalmente diferenciada de Reforma Agrária na Amazônia, sendo a subsistência baseada na agricultura familiar, no extrativismo e em atividades de baixo impacto ambiental (PORRO et al., 2015), medidas estas que concorreriam para minimizar a magnitude dos desmatamentos na região.

A implantação dessa modalidade de reforma agrária constitui um grande desafio quando feita particularmente em regiões mais críticas no que tange aos conflitos agrários relacionados à ocupação de áreas florestadas, como aquela sob influência da rodovia Transamazônica (BR-230), no estado do Pará (BRATMAN, 2011; DE SARTRE et al., 2012; PORRO et al., 2015). De acordo com Porro et al. (2015), no caso do município de Anapu, a idealização dessa proposta que articula a reforma agrária à conservação ambiental deveu-se, sobretudo na fase inicial, ao trabalho realizado pela religiosa Dorothy Stang e pela Comissão Pastoral da Terra.

Dessa forma, os estudos ambientais revestem-se de grande importância, pois podem auxiliar no entendimento dos processos de ocupação em áreas sob pressão de frentes pioneiras na Amazônia. Nestes estudos, a combinação de produtos e técnicas de sensoriamento remoto e de geoprocessamento, pela possibilidade de fornecer uma dimensão espacial e temporal à problemática, apresenta potencialidade para subsidiar políticas públicas, principalmente no que tange ao 
planejamento político e econômico para o uso adequado dos recursos naturais disponíveis (WATRIN et al., 2011). Trabalhando em projetos de assentamentos rurais no Sudeste Paraense, Watrin et al. (2005) constataram que os processos de antropização ocorridos nas propriedades estudadas tendem a apresentar trajetórias distintas, fruto das particularidades do fluxo de migração e de estrátegias de distribuição de terras. $\mathrm{O}$ processo de desflorestamento é favorecido naqueles de colonização mais antiga e com menor tamanho médio de lotes, restringindo assim a disponibilidade de recursos naturais pelo produtor.

Trabalhando em recortes de microbacias hidrográficas na região do Baixo Tapajós, estado do Pará, Rozon et al. (2015) observaram mudanças complexas e heterogêneas na dinâmica espacial e temporal de uso e cobertura da terra. Segundo esses autores, os eventos observados nos cinco grupos de bacias hidrográficas considerados podem ser explicados, em parte, pela proximidade de estradas e núcleos de povoamento.

Este trabalho consiste em analisar, a partir do emprego de geotecnologias, questões relacionadas às mudanças espaço-temporais do uso da terra e seus impactos na cobertura vegetal no PDS Anapu III e IV, no estado do
Pará. Com isto, busca-se entender como se processa a dinâmica de uso e cobertura da terra nesta categoria de projeto de assentamento rural, considerando-se como área-piloto o exemplo selecionado.

\section{Área de estudo}

A área de estudo corresponde ao PDS Anapu III e IV, conhecido como PDS Virola-Jatobá, localizado no município de Anapu, microrregião de Altamira, estado do Pará, ocupando um total de 39.486,01 hectares (Figura 1). Criado pela Portaria SR01 n³9/2002 (INCRA, 2002), o PDS consiste de um mosaico de glebas de cerca de 3.000 hectares, anteriormente destinadas a empreendedores rurais que assinaram contratos de alienação de terras públicas (CATP), mas não cumpriram com suas cláusulas, sendo a terra restituída à União. O PDS encontra-se espacialmente dividido em dois módulos distintos, sendo o PDS Anapu III destinado exclusivamente ao manejo florestal, enquanto o PDS Anapu IV abriga também os 160 lotes de uso alternativo. Tais lotes correspondem a parcelas de terra de tamanho médio de 20 hectares, destinadas ao desenvolvimento de atividades agropecuárias pelos assentados. 
Figura 1 - Localização do PDS Virola-Jatobá.
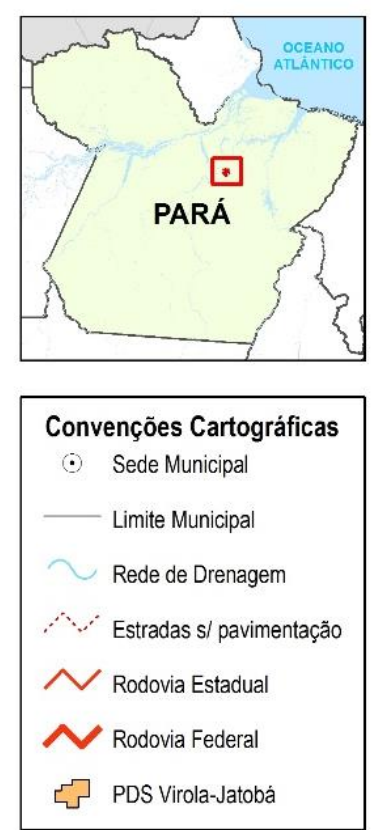

Sistema de Referência Geodésico Sistema de Projeçäo UTM Datum Oficial: SIRGAS2000 Fuso 22 S / Meridiano Central: $51^{\circ}$ WG Fonte: INCRA (2015); IBGE (2019). Elaboraçäo:Thamyres Marques

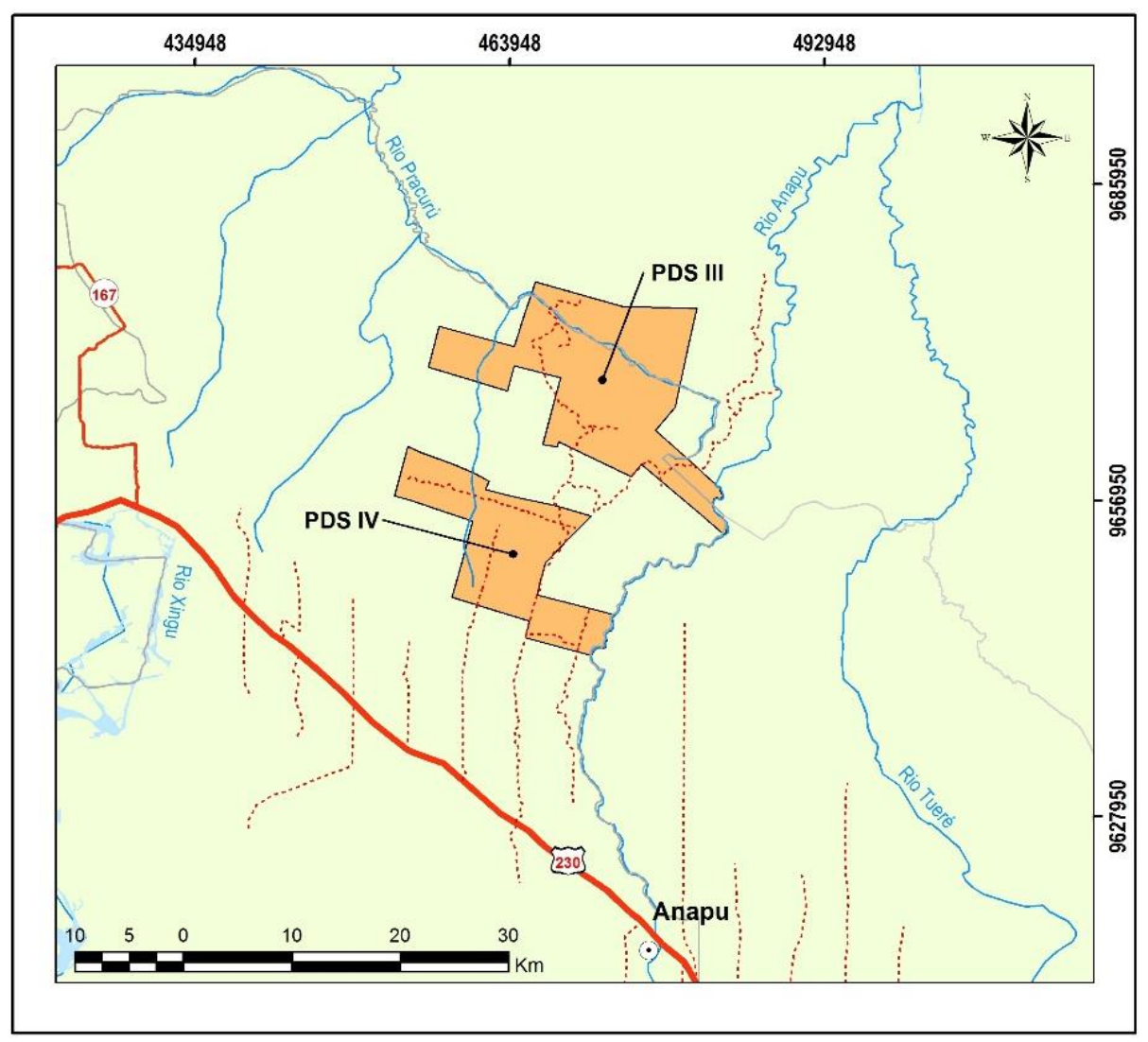

Fonte: INCRA, 2017; IBGE, 2019. Org.: dos Autores, 2019.

A área do PDS é drenada por igarapés tributários dos rios Anapu e Pracurú, sendo a malha viária existente subordinada à rodovia BR230 (Transamazônica), que corre mais ao sul desta área. Segundo Rodrigues et al. (2007), os solos ocorrentes são representados pelo Latossolo Amarelo distrófico (relevo plano a suave ondulado), Argissolo Amarelo distrófico (relevo suave ondulado a forte ondulado) e Argissolo Vermelho-Amarelo distrófico (relevo ondulado a forte ondulado). Estes solos têm em comum apresentarem boas propriedades físicas (profundos, bem drenados, boa porosidade e aeração), porém com baixa fertilidade química (elevada acidez, baixa soma de bases e baixa saturação por bases trocáveis). Tais limitações de natureza química para uso agropecuário são de fácil correção a partir de insumos agropecuários, cujo custo é, porém, inacessível à grande maioria dos produtores ali assentados.

A cobertura da terra no PDS Virola-Jatobá ainda apresenta forte predominância de floresta, sendo esta situação observada mesmo na área de uso alternativo, onde a cobertura florestal representa cerca de $70 \%$ do total. Nas áreas desflorestadas predominam pastagens, apesar da presença de pequenas roças familiares com baixa diversificação da base produtiva, onde são importantes os cultivos anuais de mandioca e milho, apesar de excepcionalmente serem ainda 
observados pequenos pomares e cultivos de cacau. Em antigas áreas de uso agropecuário abandonadas, foi favorecido o surgimento de manchas de capoeiras (sucessão secundária) com estrutura e densidades variáveis.

\section{Material e Métodos}

A partir da construção de uma base de dados espaciais na plataforma SPRING 5.3 (INPE/DPI, 2015), foram realizados o tratamento e a análise dos dados georreferenciados de interesse, considerando-se base cartográfica do IBGE, derivada para a escala 1:50.000, considerando o sistema de projeção SIRGAS 2000. Nesta base foi ainda armazenado o limite existente para a área de estudo, sendo o mesmo delineado a partir de mapa digital do imóvel disponibilizado pelo INCRA.

Para o mapeamento dos padrões de uso e cobertura da terra foram empregadas imagens Landsat, órbita/ponto 225/62, nas datas de 23/06/1984, 28/11/1989, 21/07/1994, 04/08/1999, 19/11/2003, 01/08/2004, 04/08/2005, 04/06/2006, 23/06/2007, 11/07/2008, 19/11/2009 e 04/07/2011 (Landsat 5, bandas TM 3, 4 e 5; resolução espacial 30m); 17/06/2002, 25/07/2010, 21/02/2012 e 21/10/2013 (Landsat 7, bandas ETM+ 3, 4 e 5; resolução espacial 30m); e 03/12/2014 e 15/07/2015 (Landsat 8, bandas OLI 4, 5 e 6; resolução espacial $30 \mathrm{~m})$. As imagens não foram submetidas à fase de pré-processamento, pois, atualmente, conta-se com a disponibilidade de uma larga série de imagens ortorretificadas (GUTMAN et al., 2013) e com correção atmosférica (MASEK et al., 2006), denominadas produtos de dados Landsat 8 OLI/TIRS Nível 2, que podem ser obtidas gratuitamente a partir de USGS (2015). As imagens adquiridas por meio do USGS são referenciadas ao Norte, o que torna necessário a sua reprojeção ao Hemisfério Sul.

As imagens selecionadas foram classificadas a partir de método supervisionado por regiões, sendo para isto necessário primeiramente submetê-las ao processo de segmentação, neste caso considerando os limiares de similaridade e área de 400 e 11, respectivamente. Após a geração de arquivos de contexto, as imagens foram submetidas ao processo de extração de regiões de atributos estatísticos, de modo a permitir a classificação das mesmas. A classificação das imagens propriamente dita foi realizada pelo algoritmo Bhattacharya, tendo como base a grade de segmentação gerada anteriormente. Os produtos temáticos preliminares foram analisados em levantamento de campo e posteriormente submetidos a edições temáticas de modo a reduzir erros de omissão e comissão.

No processo de classificação das imagens, foi gerada uma legenda temática compreendendo, além das classes Corpos d'Água e Nuvem/Sombra, nove unidades de mapeamento, nas quais figuram Floresta Densa e dois estágios de vegetação secundária (Capoeira Alta e Capoeira Baixa). A individualização dessas classes deve-se ao sombreamento interno promovido por suas diferenças estruturais, tais como a formação de estratos e altura do dossel (WATRIN et al., 2005). Por outro lado, a definição das classes de uso da terra considerou os estágios de desenvolvimento e as diversas práticas culturais e de manejo 
utilizadas na região. A classe Pasto Limpo referese às áreas recém-implantadas ou com baixa infestação por invasoras, características opostas às áreas definidas como Pasto Sujo. As áreas agrícolas foram definidas em função do ciclo em Culturas Anual e Perene, enquanto as áreas sob preparo de terreno foram mapeadas como as classes Queimada e Solo Exposto.

A partir da obtenção das imagens temáticas de interesse, foram realizadas a quantificação de área das classes mapeadas e a análise da dinâmica de uso e cobertura da terra nos anos em estudo. A etapa referente à análise da dinâmica de uso e cobertura da terra foi possibilitada através do cruzamento entre imagens de todas as datas consecutivas (tabulação cruzada), perfazendo um total de 16 contrastes temporais. Com base na distribuição espacial de suas informações temáticas, foram geradas matrizes de transição.

Para efeito de análise da série de imagens selecionadas, convencionou-se uma divisão em quatro fases distintas, considerando intervalos equidistantes, tomando como referência a data de instalação do PDS: pré-estabelecimento (1984, 1989, 1994 e 1999; PRÉ), pós-estabelecimento I [2002 até 2006; PÓS(1)], pós-estabelecimento II [2007 até 2011; PÓS(2)] e pós-estabelecimento III [2012 até 2015; PÓS(3)].

As análises consideraram tanto os contrastes temporais, quanto a agregação desses contrastes nas fases. Adotou-se o modelo linear geral (GLM) para os testes, considerando o efeito das fases, sendo o nível de significância adotado de $5 \%$. Tanto os testes quanto as representações gráficas foram obtidas com auxílio do programa Statistica.

\section{Resultados e Discussão}

\section{Processo de Desflorestamento}

O padrão definido pelo processo de desflorestamento na área de estudo, concentrado em quase a totalidade na área de uso alternativo, pode ser observado na Figura 2. Durante a fase de pré-estabelecimento (período 1984-1999), o desflorestamento manteve-se praticamente estável, alcançando em torno de 1.100 ha, situação não muito diferente da fase PÓS(1), na qual foram registrados incrementos anuais inferiores a 100 ha. Pode ter contribuído para este resultado o fato de, no período 1984-2005, terem sido observadas conversões gradativas de áreas de Capoeira Alta presentes na Gleba 129, para o padrão de Floresta Densa, resultantes do processo normal de sucessão vegetal nas áreas inicialmente antropizadas.

O total de desflorestamento só chegou a atingir uma taxa superior a $4 \%$ da área total (ou $1.875,5$ ha) a partir do ponto de inflexão observado em 2009 [fase PÓS(2)], sete anos após a criação do PDS. Tal constatação está ligada a uma estratégia específica de apropriação das terras nesta modalidade de regularização fundiária, pois, para Watrin et al. (2005), espera-se que os projetos de assentamento rurais apresentem maiores taxas de desflorestamento durante os primeiros anos de implantação, período de consolidação no uso das terras nos lotes. Com o passar do tempo, o avanço das atividades agropecuárias tende a esgotar as reservas florestais nos lotes, e as taxas de desflorestamento entram assim em um inexorável declínio. 
Figura 2 - Desflorestamento durante o período 1984-2015 para o PDS Virola-Jatobá, Anapu, PA. (a) Valores percentuais das áreas florestadas e desflorestadas; (b) Valores percentuais médios e desvio padrão das áreas desflorestadas considerando as fases de estabelecimento do PDS.

(a)

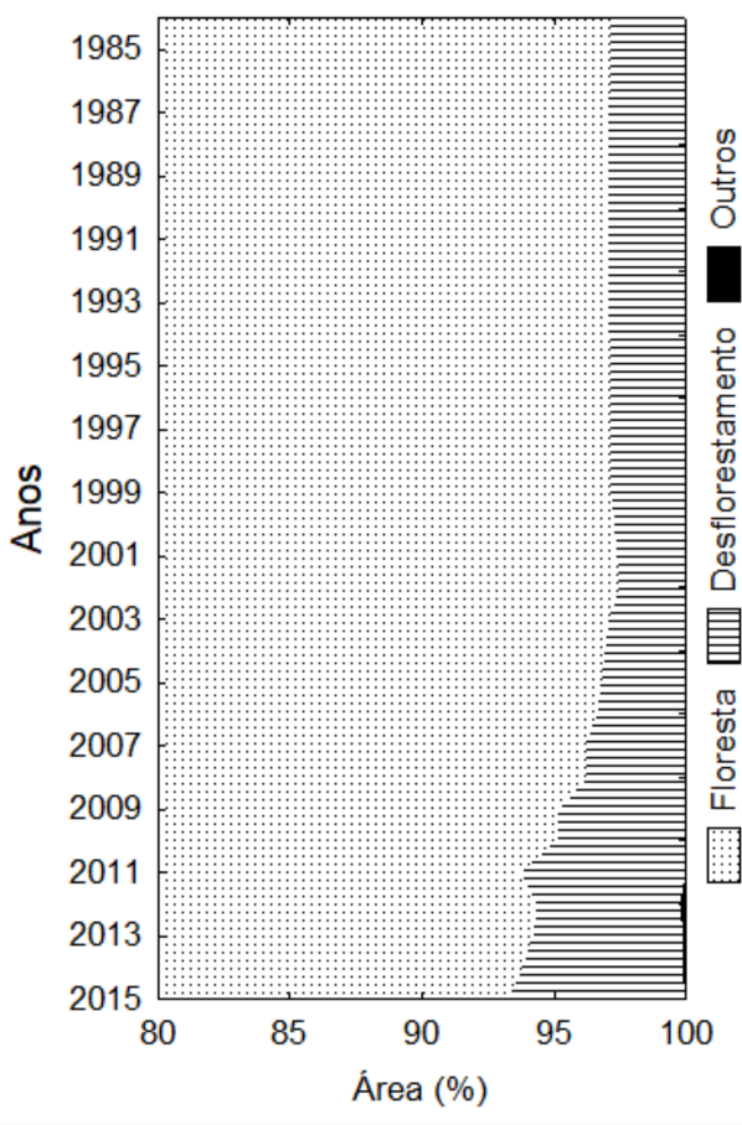

(b)

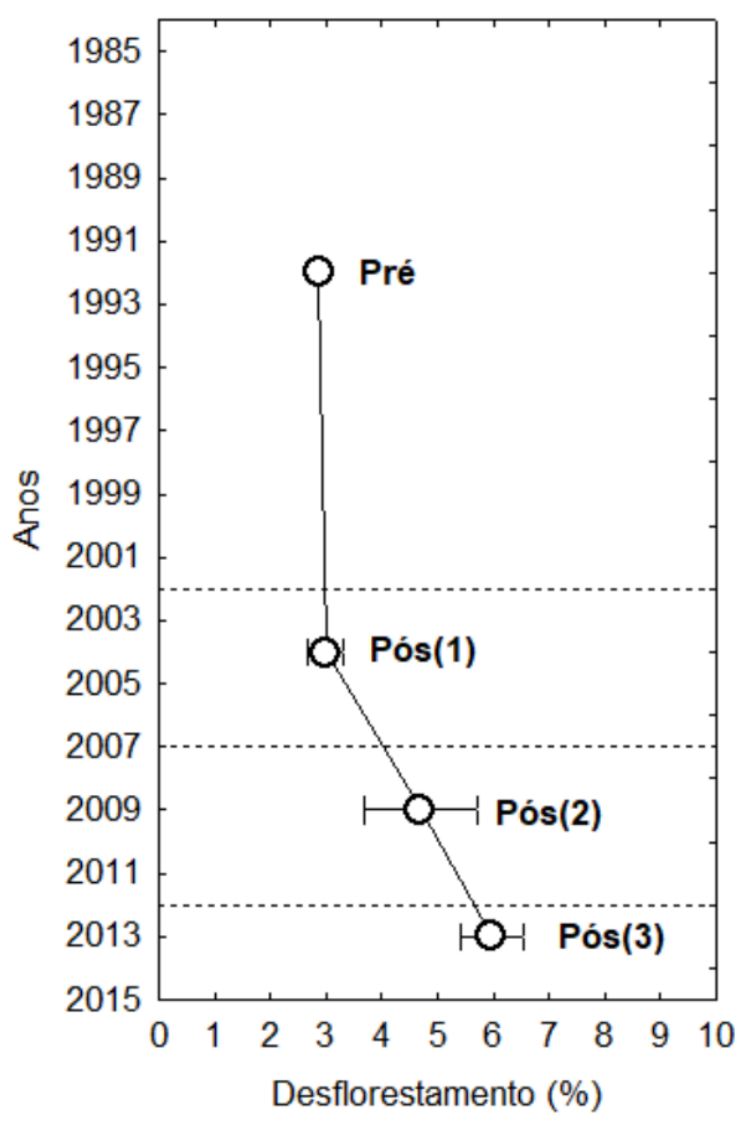

Fonte: Autores, 2019.

Considerando o total da área desflorestada já existente por ocasião da criação do PDS, uma taxa de desflorestamento equivalente no período de pós-ocupação só foi atingida em 2011 (final da fase pós-ocupação II), ocasião em que foram registrados $6,24 \%$ de áreas desflorestadas (2.467,4 ha). Apesar de a última fase analisada (2012-2015) ter sido afetada por presença de nuvens, a mesma registrou tendência de os desflorestamentos diminuírem de magnitude, pois uma parcela dos lotes atingiu os 20 ha acordados com o
INCRA para o estabelecimento de atividades agropecuárias. Outro fator que pode ter contribuído para reduzir a taxa de desflorestamento neste período é a ocorrência da iniciativa de manejo florestal entre 2008 e 2012. Ainda assim, em 2015 foi verificado o valor máximo para o desflorestamento no PDS, correspondendo a apenas $6,72 \%$ do total (2.652,8 ha).

Convém destacar que, como esperado, o processo de desflorestamento não se processou de maneira homogênea no PDS, sendo 
visivelmente mais intenso na área de uso alternativo, com proximidade ao acesso principal e que dispõe de melhor infraestrutura (Glebas 128, 129 e 130), bem como no setor correspondente ao ramal Km 115 (Glebas 128 e 130), onde os residentes divergem da modalidade PDS e não adotam o uso da terra preconizado pelo INCRA. A proximidade de núcleos de povoamento e estradas é cada vez mais reconhecida como um catalisador de mudanças espaço-temporais no uso e cobertura da terra em áreas de colonização da Amazônia (ROZON et al., 2015). Entretanto, conforme Oestreicher et al. (2014), apesar de tais fatores explicarem, em parte, as transformações no uso e cobertura da terra, só eles não podem explicar os fenômenos observados. Na verdade, para os mesmos autores, as transformações no uso e cobertura da terra constituem um reflexo de fatores econômicos, ambientais, topográficos e socioculturais das áreas estudadas.

Ao longo da série analisada, as fases préestabelecimento e início do estabelecimento [PÓS(1)] apresentaram valores de desflorestamento equivalentes, respectivamente $2,86 \pm 0,05 \%$ e $3,00 \pm 0,32 \%$. Por outro lado, tais fases apresentaram diferença significativa $(p<0,01)$ quando comparadas ao desflorestamento da fase PÓS(3) (5,97 \pm 0,56\%), enquanto a fase PÓS(2) apresentou valores intermediários $(4,69 \pm$ $1,01 \%)$. Deste modo, observou-se que mudanças promovidas na paisagem do PDS manifestaram-se somente após decorrida a fase inicial pós-estabelecimento (Figura 2b). Esse padrão de mudança na paisagem ao desflorestamento é incomum, já que na grande maioria dos casos tais mudanças ocorrem imediatamente, em oposição ao padrão mais tardio observado no PDS.

\section{Qualificação do Desflorestamento}

A paisagem, em todos os anos analisados, é dominada pela Floresta Densa, contribuindo com taxas que variam de $97,46 \%$ (2002) a 93,25\% (2015), o que denota uma paisagem em incipiente processo de transformação, típica de borda de fronteira agropecuária onde está inserida (rodovia Transamazônica). Na Figura 3 é apresentada a qualificação percentual das classes associadas às áreas desflorestadas ao longo dos anos de análise.

Em âmbito das feições de uso da terra, a classe de mais larga representatividade está associada às áreas de pastagens em seus diferentes estados, o que constitui uma realidade em muitas regiões agrárias dos distintos estados que compõe a Amazônia Legal (PROJETO TERRACLASS, 2014; PROJETO MAPBIOMAS, 2019). As áreas de pastagem atingiram uma taxa superior a $60 \%$ do total das áreas antrópicas ainda em 2011, último ano da fase de pós- estabelecimento II. Com exceção dos anos 1994 e 1999 (fase de préestabelecimento), a classe Pasto Limpo sempre apresentou taxas superiores às registradas para Pasto Sujo, sendo tal constatação mais incisiva para a última fase analisada [PÓS(3)]. 
Figura 3 - Representação da qualificação das áreas desflorestadas durante o período 1984-2015 para o PDS Virola-Jatobá, Anapu, PA.

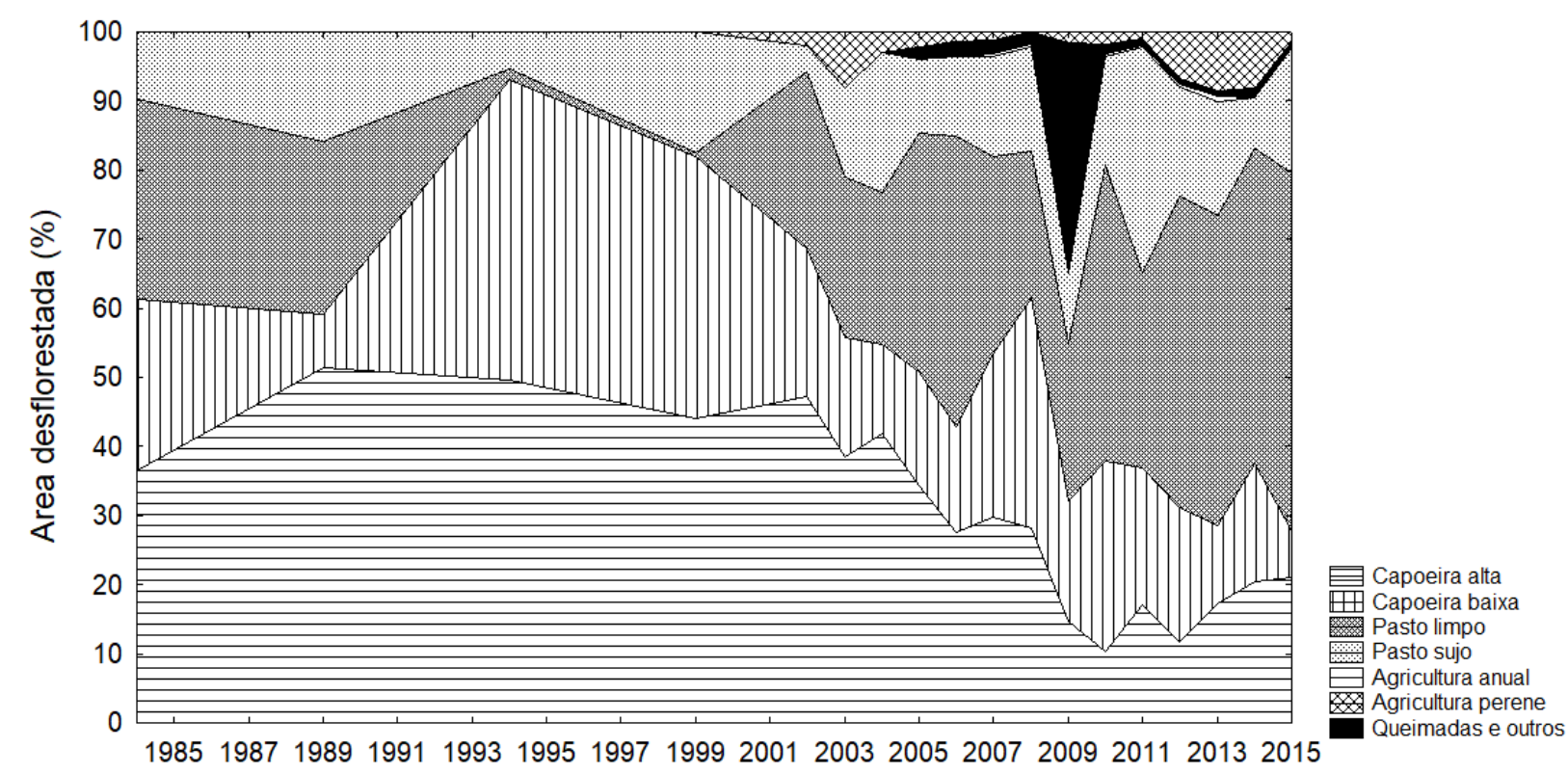

Fonte: Autores, 2019.

Isso é surpreendente considerando o baixo nível de intensificação dos sistemas agropecuários empregados na área de estudo, estando em desacordo com o observado por Watrin et al. (2005) em projetos de assentamentos rurais na região do Sudeste Paraense.

Em oposição aos resultados apresentados para pastagens cultivadas, as áreas ocupadas com agricultura são classificadas como praticamente inexpressivas durante todas as fases de pós-estabelecimento, sendo mesmo ausentes durante a fase de préestabelecimento. Neste panorama, a classe Agricultura Perene, representada sobretudo pelos cultivos de cacau, teve maior expressão em área, chegando a contribuir com a taxa máxima de 8,23\% do total das áreas antrópicas no PDS. Por outro lado, registra-se a pouca expressão das áreas com Agricultura Anual, associada aos cultivos consorciados de mandioca, milho e arroz, exibindo taxas sempre inferiores a $1 \%$. Convém salientar que o mapeamento desta classe foi bastante prejudicado não somente pelas pequenas dimensões apresentadas (roçados em torno de 1 ha), mas sobretudo pelo descompasso entre a fase de cultivo no campo (primeiro semestre do ano) e a disponibilidade de imagens Landsat (segundo semestre do ano). A disponibilidade de imagens nos meses específicos de outubro e novembro (mais secos) implicou também na possibilidade de serem mapeadas áreas em preparo do solo a partir de queimadas. Considera-se, portanto, a possibilidade de parte das áreas classificadas espectralmente nestes meses como Pasto Sujo referir-se a cultivos agrícolas anuais após a fase de colheita (do milho e arroz, em maio-junho), cujos restos 
culturais estão associados à mandioca e à vegetação secundária emergente.

\section{Dinâmica de uso e cobertura da terra}

Como reflexo do baixo impacto das atividades antrópicas no PDS, as áreas de Floresta Densa apresentaram, em todo o período de análise, altas taxas de estabilidade, cujos menores valores foram observados durante as fases de pós- estabelecimento 2 e 3 , sendo o mínimo de 97,79\%, para o período 2012-2013 (Figura 4a). Tal comportamento se aproxima mais de áreas com paisagem já consolidada, onde os modestos remanescentes florestais, em sua maior parte, estão circunscritos às margens da rede de drenagem, em áreas desfavoráveis para o desenvolvimento de atividades produtivas, como observado por Metzger (2002) em antiga área de colonização no nordeste do estado do Pará. As áreas que não permaneceram estáveis foram convertidas preferencialmente para o uso de terra dominante, ou seja, pastagem, em particular Pasto Limpo, que, com exceção da fase de pré-estabelecimento, teve a sua origem em áreas florestais, com taxas médias variando de $49,7 \%$ a $55,2 \%$. Contudo, observações em campo indicam que raramente ocorre esta conversão direta, sendo a mesma resultante de um primeiro ano em que, após o desflorestamento, ocorre o cultivo anual (durante o primeiro semestre do ano), sendo que o semeio de capim ocorre concomitante às últimas capinas do cultivo anual.

Por outro lado, as áreas com sucessão secundária indicaram comparativamente menores taxas de estabilidade (Figura $4 b$ ), pois sua presença está associada como elemento de pousio agrícola em unidades de produção familiar. Nesse contexto, vale destacar que os estágios de sucessão apresentaram comportamento diferenciado, sendo para Capoeira Alta registradas taxas de estabilidade bem mais altas que as observadas para Capoeira Baixa, conforme também observado por Watrin et al. (2005) e Rozon et al. (2015). Entretanto, considerando o baixo antropismo da área de estudo, as maiores taxas de conversão entre unidades de cobertura vegetal ocorreram entre si (Floresta Densa, Capoeira Alta e Capoeira Baixa).

Dentre as classes de uso da terra em áreas antropizadas, as pastagens (Figura 4c) descreveram as taxas de estabilidade mais expressivas, apresentando, porém, diferenciações entre as classes Pasto Limpo e Pasto Sujo. Pasto Limpo definiu sempre as maiores taxas de estabilidade durante as fases de pós-estabelecimento, sendo o valor máximo de $68,67 \%$ observado no período 2011-2012, em oposição a taxas muito baixas observadas em alguns anos da fase de pré-estabelecimento (mínimo: 0,16\%). As taxas de estabilidade mais baixas registradas para Pasto Sujo estão associadas ao fato que as mesmas vêm sendo parcialmente convertidas novamente para Pasto Limpo, a partir da prática de reforma das pastagens degradadas, considerando o uso do fogo. 
Figura 4 - Taxas de estabilidade apresentadas durante o período 1984-2015 pelas principais classes de uso e cobertura da terra no PDS Virola-Jatobá, Anapu, PA.

(a)

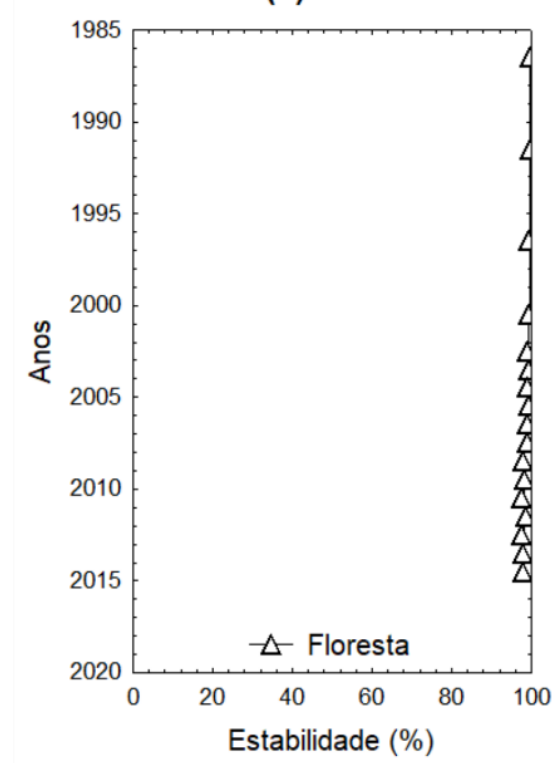

(b)

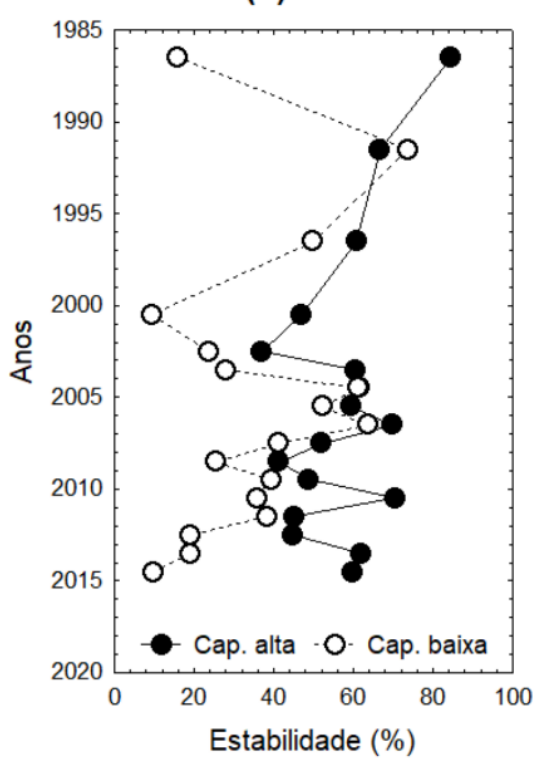

(c)

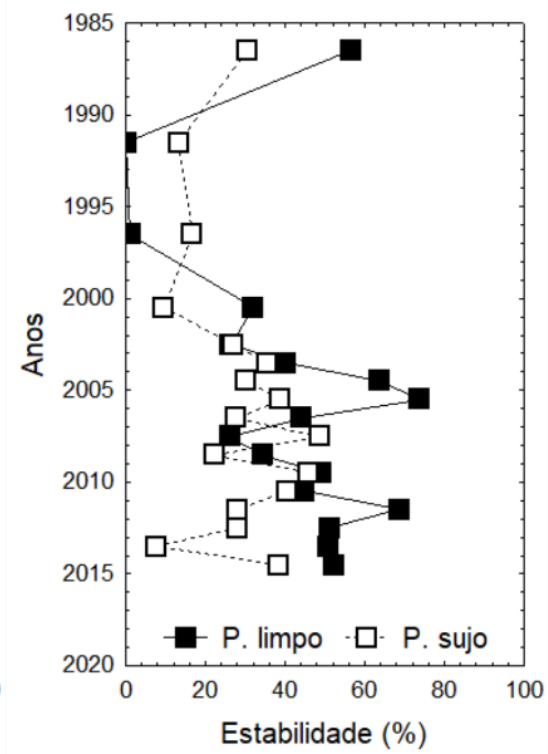

Fonte: Autores, 2019.

Enquanto parte das áreas de Pasto Sujo que não permanecem estáveis são convertidas para Pasto Limpo, uma outra parcela das mesmas pode vir a ser convertida para o padrão associado à Capoeira Baixa, devido ao abandono continuado e ao inexorável avanço do processo de sucessão vegetal.

Por fim, as reduzidas áreas agrícolas mapeadas (Agricultura Anual e Agricultura Perene) foram implantadas preferencialmente em áreas de Floresta Densa, aproveitando a camada orgânica de maior fertilidade natural. Como os sistemas de produção adotados têm o caráter predominante de agricultura itinerante, a estabilidade da classe Cultura Anual nos períodos analisados foi bastante variável.

Aparentemente, os resultados alcançados dão indícios fortes que o modelo de assentamento da área de estudo tem limitado o processo de antropização desordenado observado em outras regiões da Amazônia. No entanto, tal esforço traz um complexo ônus socioeconômico que constitui um grande desafio a ser superado pelas políticas públicas em projetos de desenvolvimento sustentável. A Figura 5 demonstra a espacialização da pricipais classes do uso e cobertura do solo no ano de 1984 - fase [Pré] e para o ano 2015 - fase [Pós(3)]. 
Figura 5 - Uso e cobertura da terra para os anos 1984 e 2015 do PDS Virola-Jatobá, Anapu, PA.

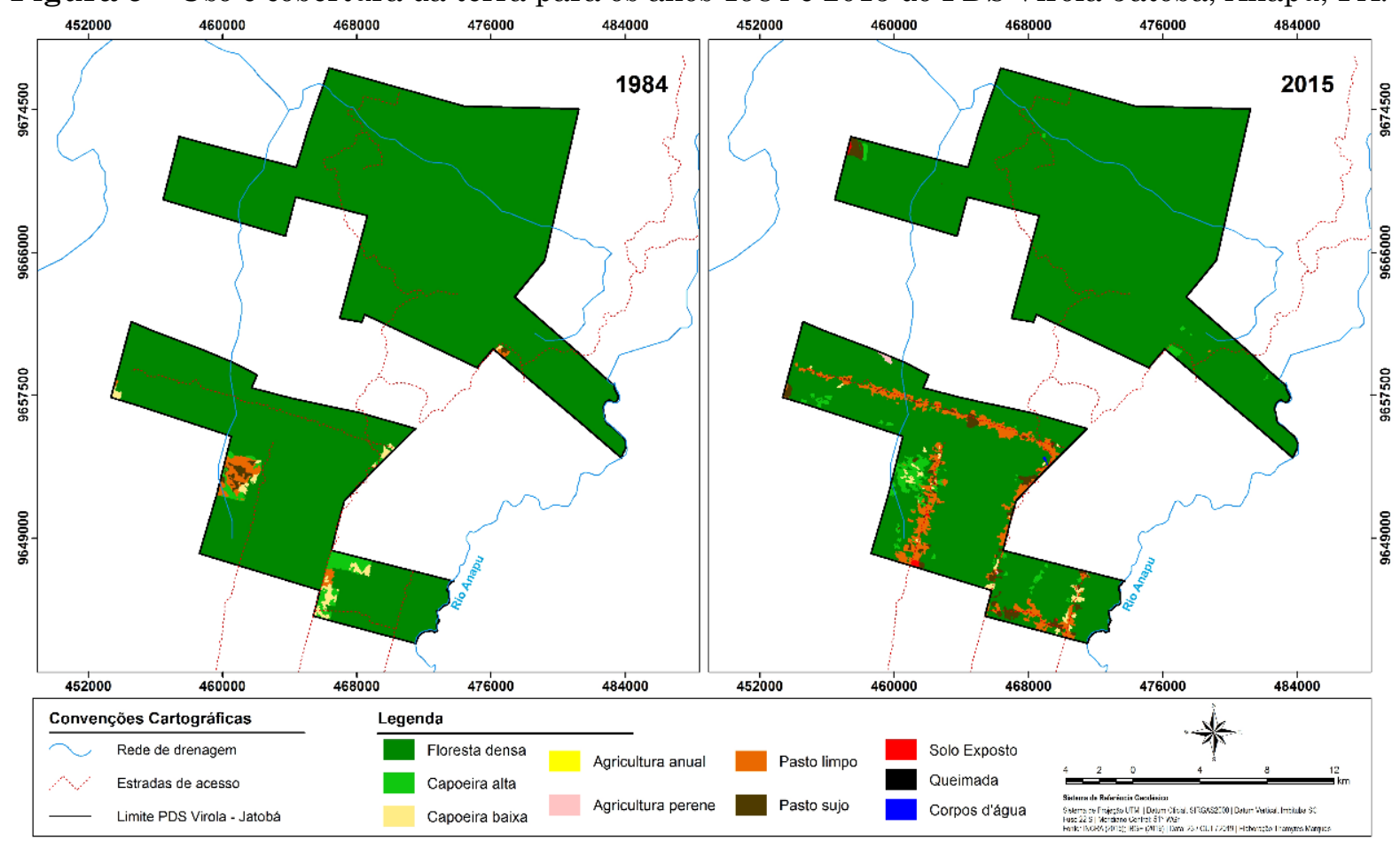

Fonte: Autores, 2019.

\section{Considerações Finais}

Durante as fases iniciais de análise, o desflorestamento manteve-se praticamente estável, ocasionalmente registrando incrementos anuais muito modestos, de modo que uma taxa mais proeminente só foi registrada sete anos após a criação do PDS. Tal comportamento está ligado a uma estratégia específica de apropriação das terras nesta modalidade de regularização fundiária, já que era esperado que as maiores taxas de desflorestamento ocorressem nos primeiros anos da implantação do assentamento. Houve tendência de redução destas taxas na última fase analisada, pois alguns lotes atingiram os
20 ha previamente definidos para o uso agropecuário.

A paisagem da área de estudo é dominada substancialmente pela classe Floresta Densa, o que denota um estado de incipiente processo de transformação, típica de região de borda de fronteira agropecuária. As classes de uso da terra dominantes em áreas antropizadas estão associadas a pastagens em seus diferentes estados, sendo bem mais representativa a classe Pasto Limpo. Ausentes na fase de préestabelecimento, as áreas agrícolas são quase inexpressivas durante todas as fases de pósestabelecimento.

Verificou-se que as áreas de Floresta Densa apresentaram, no período analisado, altas taxas de estabilidade, mais comumente 
associadas a antigas áreas de colonização, com paisagem consolidada, ou ainda áreas nas quais a pressão antrópica é reduzida, como reservas extrativistas ou terras indígenas. Comparativamente, as áreas de sucessão secundária descreveram menores taxas de estabilidade, pois atuam como elemento ativo de pousio agrícola na produção familiar, principalmente o estágio de Capoeira Baixa.

Para o uso da terra, as pastagens apresentaram as taxas de estabilidade mais expressivas, com Pasto Limpo definindo os maiores valores, em oposição ao observado para Pasto Sujo, que registrou certa dinamicidade. Como os sistemas de produção adotados têm o caráter predominante de agricultura itinerante, as taxas de estabilidade da classe Cultura Anual foram geralmente baixas.

\section{Agradecimentos}

Este trabalho foi realizado em âmbito do projeto "Governança local e sustentabilidade do manejo florestal de base comunitária nos projetos de desenvolvimento sustentável em Anapu, Transamazônica - AutoManejo". O mesmo contou com suporte financeiro do Macroprograma 6 e do Portfólio de Recursos Florestais Nativos da Embrapa, assim como da Fundação Amazônia Paraense de Amparo à Pesquisa - FAPESPA (ICAAF 104/2014). Os autores agradecem ao Geógrafo João Felipe Cerqueira Pinto, da FUNCATE, pelo apoio no processo de auditoria de classificação das imagens de satélite empregadas neste trabalho.

\section{Referências}

BRASIL. Lei n ${ }^{0} 11.284$ de 02 mar. 2006. Dispõe sobre a gestão de florestas públicas para a produção sustentável. 2006. Disponível em: $<$

http://www.planalto.gov.br/ccivil_03/_Ato20 04-2006/2006/Lei/L11284.htmf>. Acesso em: 29 maio 2015.

BRATMAN, E. Z. Villains, victims, and conservationists? Representational frameworks and sustainable development on the Transamazon Highway. Human Ecology, v. 39, p. 441-453. 2011. https://doi.org/10.1007/s10745-011-9407-x

DE SARTRE, A. X.; BERDOULAY, V.; LOPES, R. S. Eco-frontier and place-making: the unexpected transformation of a sustainable settlement project in the Amazon. Geopolitics. v. 17, n. 3, p. 578-606, 2012. https://doi.org/10.1080/14650045.2011.6311 99

FOLEY, J. A.; DEFRIES, R.; ASNER, G. P.; BARFORD, C.; BONAN, G.; CARPENTER, S. R.; CHAPIN, F. S.; COE, M. T.; DAILY, G. C.; GIBBS, H. K.; et al. Global consequences of land use. Science, v. 309, p. 570-574, 2005.

https://doi.org/10.1126/science.1111772

GUTMAN, G.; HUANG, C.; CHANDER, G.; NOOJIPADY, P.; MASEK, J. G. Assessment of the NASA-USGS Global Land Survey (GLS) datasets. Remote Sensing of Environment, n. 134, p. 249-265, 2013. https://doi.org/10.1016/j.rse.2013.02.026

HANSEN, M. C.; POTAPOV, P. V.; MOORE, R., HANCHER, M.; TURUBANOVA, S. A.; TYUKAVINA, A.; KOMMAREDDY, A; et al. High-resolution global maps of 21st-century forest cover change. Science, v. 342, p. 850853 , 2013. https://doi.org/10.1126/science.1244693

INSTITUTO NACIONAL DE COLONIZAÇÃO E REFORMA AGRÁRIA (INCRA). Portaria $\mathrm{n}^{\circ} 477$ de 04 nov. 1999. Diário Oficial da União. Brasília, 1999. Disponível em: <http://www.incra.gov.br/sites/default/files/ uploads/institucional/legislacao--/ portarias/portarias-de1999/portaria_incra_p477_041199.pdf>. Acesso em: 29 maio 2015.

INSTITUTO NACIONAL DE COLONIZAÇÃO E REFORMA AGRÁRIA (INCRA). Portaria 
$\mathrm{n}^{0} 39$ de 13 nov. 2002. Diário Oficial da União. Brasília, 2002. Disponível em: < http://portal.incra.gov.br/sites/default/files/ uploads/institucionall/legislacao--

/portarias/portarias-de-

2002/portaria_incra_p39_131102.pdf>.

Acesso em: 29 maio 2015.

INSTITUTO NACIONAL DE COLONIZAÇÃO E REFORMA AGRÁRIA (INCRA). Portaria $\mathrm{n}^{\circ} 1040$ de 12 dez. 2002. Diário Oficial da União. Brasília, 2002. Disponível em: < https://www.normasbrasil.com.br/norma/po rtaria-1040-2002_182498.html>. Acesso em: 29 maio 2015.

INSTITUTO NACIONAL DE PESQUISAS ESPACIAIS/ DIVISÃO DE PROCESSAMENTO DE IMAGENS (INPE/ DPI). Spring: Sistema de processamento de informações georreferenciadas. Disponível em: <http://www.dpi.inpe.br/spring>. Acesso em: 11 maio 2015.

LAURANCE, W. F.; CAMARGO, J. L. C.; LUIZÃO, R. C. C.; LAURANCE, S. G.; PIMM, S. L.; BRUNA, E. M.; STOUFFER, P. C.; WILLIAMSON, B.; et al. The fate of Amazonian forest fragments: a 32-year investigation. Biological Conservation, v. 144, p. 56-67, 2011. https://doi.org/10.1016/j.biocon.2010.09.021

MASEK, J. G.; VERMOTE, E. F.; SALEOUS, N. E.; WOLFE, R.; HALL, F. G.; HUEMMRICH, K. F.; FENG, G.; KUTLER, J.; LIM, T. K. A Landsat surface reflectance dataset for North America, 1990-2000. IEEE Geoscience and Remote Sensing Letters, v. 3, n. 1, p. 68-72. 2006. https://doi.org/10.1109/LGRS.2005.857030

METZGER, J. P. Landscape dynamics and equilibrium in areas of slash-and-burn agriculture with short and long fallow period (Bragantina region, NE Brazilian Amazon). Landscape Ecology. n. 17, p. 419-431, 2002.

https://doi.org/10.1023/A:1021250306481

OESTREICHER, J. S.; FARELLA, N.; PAQUET, S.; DAVIDSON, R.; LUCOTTE, M.; MERTENS, F.; SAINT-CHARLES, J. Livelihood activities and land-use at a riparian frontier of the Brazilian Amazon: quantitative characterization and qualitative insights into the influence of knowledge, values and beliefs. Human
Ecology, v. 42, n. 4, p. 521-540, 2014. https://doi.org/10.1007/s10745-014-9667-3

PORRO, R.; PORRO, N. S. M.; MENEZES, M. C.; BARTHOLDSON, Ö. Collective action and forest management: institutional challenges for the environmental agrarian reform in Anapu, Brazilian Amazon. International Forestry Review, v. 17, n. $1, \quad$ p. $20-37, \quad 2015$. https://doi.org/10.1505/14655481581466899 0

PROJETO MAPBIOMAS - Coleção 4 da Série Brasileira de Mapas de Cobertura e Uso da Terra. Disponível em: http://plataforma.mapbiomas.org/map\#tran sitions. Acesso em: 24 out. 2019.

PROJETO TERRACLASS - 2012: mapeamento do uso e cobertura da terra na Amazônia Legal Brasileira. Brasília, DF: Embrapa; São José dos Campos: Inpe, 2014. [37 p.]. Disponível em: <http://www.inpe.br/noticias/arquivos/pdf/T erraClass_2012.pdf $>$. Acesso em: 16 jun. 2016.

RODRIGUES, T. E.; SILVA, R. C.; SILVA, B. N. R.; SILVA, J. M. L. VALENTE, M. A.; DARIVA, T. A.; JESUS, A. S.; VENTURIERI, A. Caracterização, mapeamento e classificação dos solos da área de influência da BR-163 (CuiabáSantarém) e BR-230 (Transamazônica), no Estado do Pará. In: VENTURIERI, A. (Ed.). Zoneamento ecológico-enonômico da área de influência da BR-163 (Cuiabá Santarém). Belém, PA: Embrapa Amazônia Oriental. v. 2, p. 403-573, 2007.

ROZON, C.; LUCOTTE, M.; DAVIDSON, R.; PAQUET, S.; OESTREICHER, J. S.; MERTENS, F.; PASSOS, C. J. S.; ROMANA, C. Spatial and temporal evolution of familyfarming land use in the Tapajós region of the Brazilian Amazon. Acta Amazonica. v. 45, n. $2, \quad$ p. $203-214,2015$. https://doi.org/10.1590/1809-4392201401384

SORRENSEN, C. Potential hazards of land policy: Conservation, rural development and fire use in the Brazilian Amazon. Land Use Policy, v. 26, n. 3, p. 782-791, Jul. 2009. https://doi.org/10.1016/j.landusepol.2008.10. 007

VERBURG, P. H.; VAN DE STEEG, J.; VELDKAMP, A.; WILLEMEN, L. From land cover change to land function dynamics: a 
major challenge to improve land characterization. Journal of Environmental Management, v. 90, n. 3, p. 1327-1335, 2009. https://doi.org/10.1016/j.jenvman.2008.08.0 05

UNITED STATES GEOLOGICAL SURVEY (USGS). Disponível em: <http://earthexplorer.usgs.gov/>. Acesso em: 06 jul. 2015.

WATRIN, O. S.; CRUZ, C. B. M.; SHIMABUKURO, Y. E. Análise evolutiva da cobertura vegetal e do uso da terra em projetos de assentamentos na fronteira agrícola amazônica, utilizando geotecnologias. Geografia, v. 30, n. 1, p. 5976, jan./abr. 2005.

WATRIN, O. S.; OLIVEIRA, P. M.; OLIVEIRA, R. R. S. Padrões antrópicos e fisiográficos definindo unidades de paisagem na Reserva Extrativista 'Verde Para Sempre', Porto de Moz, PA. Geografia. v. 36, n. 3, p. 535-549, set./dez. 201 